\title{
Preference for signaled or unsignaled shock in goldfish
}

\author{
CAROLINE FISHER and PIETRO BADIA \\ Bowling Green State University, Bowling Green, Ohio 43403
}

\begin{abstract}
Unsignaled, inescapable shocks were presented to five goldfish. By making a shuttle response, subjects could change the condition to signaled shocks for $2 \mathrm{~min}$, after which unsignaled shocks were automatically reinstated. All subjects changed from the unsignaled to the signaled condition. Three different extinction conditions were administered, to assess the extent to which the shock and shock-free periods controlled changeover performance. The performance of the fish was compared with the performance of rats obtained in previous studies. This comparison showed a number of similarities. The argument, by some, that subjects choose the signaled shock condition because of modifiable shock, was disputed.
\end{abstract}

Several studies have shown that rats will choose a signaled over an unsignaled shock condition (e.g., Badia \& Culbertson, 1972; Badia, Culbertson, \& Lewis, 1971). In these studies, subjects could change the shock schedule from an unsignaled to a signaled one for brief time periods by pressing a changeover lever. It was found that rats changed to the signaled condition whether shock was avoidable, escapable, or inescapable.

Badia and Culbertson (1972) and Badia et al. (1971) analyzed the data in terms of shock and shock-free periods and hypothesized that the choice of the signaled shock condition was controlled by the stimulus conditions in the shock-free periods. The present study assessed whether similar findings would obtain in goldfish. While the studies previously cited used rats, there is also some evidence that pigeons (Griffin, Honaker, Jones, \& Pynes, 1974) and humans (Badia, Culbertson, \& Harsh, 1974) prefer signaled over unsignaled shock. The use of goldfish also allows one to rule out arguments that preference for the signaled condition is based upon unauthorized avoidance or upon the modifiability of shock by certain responses.

\section{METHOD}

Five naive goldfish, 6 to $8 \mathrm{~cm}$ in length, were obtained from a local pet shop to serve as subjects. The fish were fed daily throughout the experiment at least $1 \mathrm{~h}$ after the experimental sessions.

All subjects were tested in an aquatic shuttlebox (Testan Scientific Instruments, Davis, California) with round chambers, $10 \mathrm{~cm}$ in diam, and a round connecting tunnel, $2 \mathrm{~cm}$ in diam. The $.5-\sec 8-\mathrm{V}$ dc shocks were delivered to the chamber in which the fish was located through two curved electrodes, each covering a 90-deg arc of the chamber wall. The electrodes were positioned opposite one another, equidistant from the tunnel. Two GI 1820 lamps were located opposite the tunnel outside each chamber. One had a red lens cover and served as the 5-sec signal preceding shock in the signaled situation. The other, with an amber lens cover, served as the stimulus identifying the shock situation as signaled or unsignaled. For three subjects, the amber

This research was supported in part by Grant BG-33725 to Pietro Badia and by a predoctoral fellowship to the first author, both from the National Science Foundation. Reprints may be obtained from Pietro Badia, Department of Psychology, Bowling Green State University, Bowling Green, Ohio 43403. light served as the correlated stimulus for the signaled situation, while the unsignaled schedule operated during darkness. These correlated stimuli (amber light vs. dark) were reversed for the other two subjects.

Two photocells, located along the tunnel connecting the two chambers, were used to determine when the subject swam from one chamber to the other. A shuttle response was recorded after the successive breaking of the two photocell beams.

Subjects were run in 90-min sessions every second day. Shock in all conditions was delivered on a VT 120-sec schedule determined from the tables of Fleshler and Hoffman (1962), modified so that the shortest interval was $5 \mathrm{sec}$. Shock was unavoidable and inescapable at all times, and the intensity was equivalent no matter what position the fish adopted.

\section{Initial Training}

All subjects were exposed for a minimum of three 90-min sessions to an unsignaled schedule and for a minimum of three sessions to a signaled schedule. During the latter sessions, the correlated stimulus was always on and the 5-sec red light always preceded shock. Shuttle responses and the amount of time that would have been spent in the changeover condition, had the contingency been in effect, were recorded, although these responses produced no stimulus changes.

\section{Changeover for Signaled Shock (CO)}

Following initial training, subjects began the next session with the unsignaled shock schedule. A shuttle response resulted in the onset of the correlated stimulus and initiated the signaled schedule. One changeover response produced the correlated stimulus and signaled schedule for a 2 -min period. Additional responses during this 2 -min period were recorded, but were ineffective. At the end of the period, the correlated stimulus terminated and subjects could remain in the unsignaled schedule or reinstate the signaled one by making another changeover response. A 2-sec changeover delay (COD) was used with all subjects. Additionally, any signals scheduled to occur immediately after a changeover was acquired were delayed for $2 \mathrm{sec}$.

\section{Changeover Extinction 1 (EXT 1)}

Under this extinction procedure, subjects always remained in the unsignaled condition. Neither the correlated stimulus nor the signal was presented following changeover responses. This condition allowed evaluation of the effects on changeover responding exerted by both the correlated stimulus and a signal.

\section{Changeover Extinction 2 (EXT 2)}

Effects of the correlated stimulus alone were evaluated with this procedure. Again the subjects received only unsignaled shock. Changeover responses produced only the correlated stimulus, but not the signal, for 2-min periods. 


\section{Changeover Extinction 3 (EXT 3)}

Effects of presenting the signal alone, without the accompanying correlated stimulus, were examined under the final extinction procedure. A changeover response initiated the signaled schedule for 2 -min periods, but did not produce the correlated stimulus. Thus, by maintaining a sufficient rate of changeover responding, subjects could remain in the signaled condition but with no correlated stimulus to identify it.

\section{Stability Criterion}

All subjects remained under each changeover condition until a stability criterion was met. This criterion was three successive sessions during which the time spent in changeover during the third session did not vary more than $10 \%$ from the time spent in the preceding sessions. Deaths caused exceptions to this criterion.

\section{RESULTS}

The data clearly show that all subjects chose signaled over unsignaled shock. Each subject acquired the changeover response within the first four sessions. The removal of the changeover contingency (EXT 1) resulted in changeover responding returning to baseline levels. Changeover responding was quickly reacquired when the contingency was reinstated and remained at the high levels when responding produced the correlated stimulus alone (EXT 2). Baseline levels of responding were found when signals, but no correlated stimuli, were produced (EXT 3). Choice of signaled shock was not affected by the order of exposure to the signaled and unsignaled situations in training, or by the stimulus (amber light or dark) correlated with the signaled schedule.

Acquisition and stabilization of the changeover response were generally quite rapid. Two subjects acquired the response during the first session; one required two sessions; one, three; and one, four. Responding stabilized within 5, 6, and 7 sessions for Subjects K, L, and G, respectively. An apparatus failure necessitated a return to training conditions after $\mathrm{CO}$ responding had been acquired by Subjects $\mathrm{R}$ and $\mathrm{N}$. However, they stabilized within 7 and 9 sessions respectively, when again placed in $\mathrm{CO}$.

Figure 1 contains a portion of a typical event record (Subject R, Session 26), illustrating stable changeover responding. The performance of Subject $R$ could be described as average both on percent of time spent in the signaled condition and total number of responses. This record indicates both that more responses were made than necessary to reinstate the signaled condition and that the signaled condition was reinstated fairly rapidly after the 2-min signaled period had timed out. A comparison with the record presented by Badia and Culbertson (1972) for rats suggests that the stimulus control was not as complete for fish. First, the rat reinstated the signal condition more quickly after it had timed out, and, second, the rat did not make many excess $\mathrm{CO}$ responses.

The difference in the speed of reinstating the signaled condition can also be seen in the summary graph (Figure 2). The data points represent the percent time spent in the changeover condition for each subject during the last three sessions of each condition experienced. The percent of time spent in the signaled situation during $\mathrm{CO}$ varied considerably between animals (range of $42 \%$ to $89 \%$ ), and only Subject K spent better than $80 \%$ of the time in the signaled condition. Variation between animals in the percent time spent in the changeover condition occurred during training and EXT 1. However, every animal spent considerably more time in the signaled situation when given the opportunity, relative to their baseline performance.

For the two subjects receiving all extinction condition, the percent of time spent in the changeover condition was almost as high during EXT 2, when a response resulted in two minutes of the correlated stimulus but no signals, as during the regular $\mathrm{CO}$ condition. The same two subjects showed a decrease in changeover responding during EXT 3, when responding resulted in periods of signaled shock but no correlated stimulus. The levels were comparable to their performance during EXT 1. The percent time spent in the signaled condition again increased when the $\mathrm{CO}$ contingency was reinstated.

\section{DISCUSSION}

In general, the fish in the present study responded much like the rats in previous studies (Badia \& Culbertson, 1972; Badia et al., 1971). They changed from an unsignaled condition to one that included both correlated stimulus and signal (CO) and responded for the condition of correlated stimulus alone (EXT 2) at high rates. However, as with rats, changeover responding decreased dramatically when neither stimulus was presented (EXT 1) or when the signal without the correlated stimulus was presented (EXT 3).

These data indicate that goldfish choose signaled over unsignaled shock situations, even though the shock is unavoidable and inescapable. Observation of each fish indicated no tendency to orient in any direction during the signal preceding shock, although increased swimming activity was noted. Thus, the fish apparently were not attenuating the 
aversiveness of the shock by adopting any bodily orientation. The present results do not support the contention of Biederman and Furedy $(1970,1973)$ that signaled shock is preferred because it allows modification of shock intensity or because of photic stimulation. The question of photic stimulation apparently resulted from a careless reading of the literature, since the very study that Biederman and Furedy cite (Badia \& Culbertson, 1972) had the necessary controls, as did other studies investigating the signaled shock phenomena (e.g., Badia et al., 1971). Two recent studies also cast doubt upon their modification of shock hypothesis. Griffin et al. (1974) found that pigeons preferred signaled over unsignaled shock delivered through implanted electrodes. Similarly, rats showed a preference for signaled shock even though it was delivered through fixed tail electrodes (Miller, Daniel, \& Berk, 1975). In both of these studies, as well as the present one, shock intensity could not be easily modified. Additionally, rats were found to prefer signaled shock that was four to nine times longer or two to three times more intense than unsignaled shock (Badia, Culbertson, \& Harsh, 1973).

The factor controlling the choice of the signaled shock situation in the present study, as well as in previous studies, appears to be the correlated stimulus identifying a shock-free period. Changeover responding was high if this correlated stimulus was produced and low if it was not. (See Badia \& Culbertson, 1972, for a more complete discussion.) Additional support for the control exerted by the correlated stimulus stems from previous unpublished work by the authors that failed to find any preference for signaled or unsignaled shock in goldfish. In that attempt, signals scheduled to occur immediately after a changeover response were not delayed. Thus, a response was occasionally followed by a signal rather than by a correlated stimulus. Changeover responding was erratic, varying dramatically from session to session. No clear preference could be determined for any subject tested. The presentation of the correlated stimulus immediately following a response would appear to be necessary to maintain responding, while the presentation of the signal after a response tends to disrupt responding. Evidence by Harsh and Badia (1974) also indicates that the pattern of food responding in the presence of stimuli identify ing shock and shock-free periods is very different. (Note that suppression and facilitation occurred.)

Acquisition and stabilization took more sessions for the fish in this study than for rats (Badia \& Culbertson, 1972; Badia et al., 1971); however, the sessions for the fish were only one-fourth as long as for the rats. The major difference between the performance of the goldfish in this study and that of rats in the studies cited previously is the number of extra changeover responses that occurred. The fish made a high number of these responses. One possible reason for these extra responses is that a shock situation elicits swimming and shuttle responding in fish (Woodard \& Bitterman, 1971). This possibility seems tenable since a good proportion of the extra responses occurred immediately following shock (during the COD) or during signals. This, however, did not bias results since these responses did not produce the signaled condition. Despite the higher number of excess responses, the fish chose signaled over unsignaled shock, and this choice was controlled by the stimulus identifying shock-free periods.

\section{REFERENCES}

Badia, P., \& Culbertson, S. The relative aversiveness of signalled versus unsignalled escapable and inescapable shock. Journal of the Experimental Analy sis of Behavior, 1972, 17, 463-471.

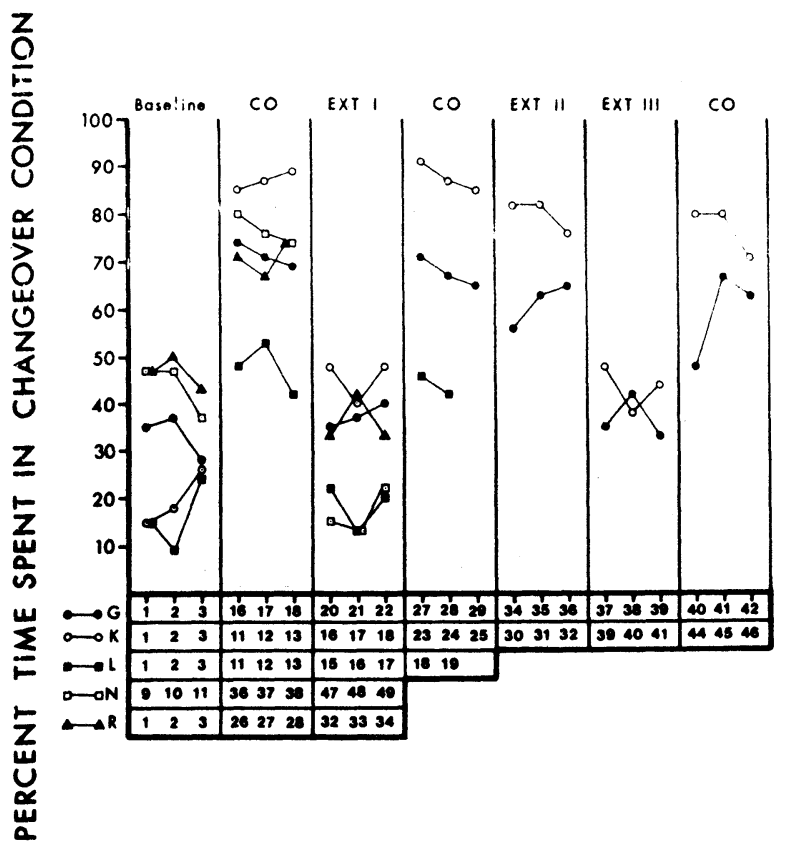

NINETY MINUTE SESSIONS

Figure 2. Percent of session time spent in changeover during the last three sessions of each condition.

Badia, P., Culbertson, S., \& Harsh, J. Choice of longer or stronger signalled shock over shorter or weaker unsignalled shock. Journal of the Experimental Analysis of Behavior, 1973,19, 25-32.

Badia, P., Culbertson, S., \& Harsh, J. Relative aversiveness of signalled vs unsignalled avoidable and escapable shock situations in humans. Journal of Comparative and Physiological Psychology, 1974, 87, 338-346.

Badia, P., Culbertson, S., \& Lewis, P. The relative aversiveness of signalled vs unsignalled avoidance. Journal of the Experimental Analysis of Behavior, 1971, 16, 113-121.

Biederman, G. B., \& Furedy, J. J. The preference-for-signalled-shock phenomenon: Signalling shock is reinforcing only if shock is modifiable. Quarterly Journal of is reinforcing only if shock is modifiable. Qua

Biederman, G. B., \& Furedy, J. J. Preference-for-signaled-shock phenomenon: Effects of shock modifiability and light reinforcement. Journal of Experimental Psychology, 1973. 100, 380-386.

Fleshler, M., \& Hoffman, H. S. A progression for generating variable-interval schedules. Journal of the Experimental Analysis of Behavior, 1962, 5, 529-530.

Griffin, P., Honaker, L. M., Jones, D. E., \& Pynes, L. T. Preference for signaled vs unsignaled shock in pigeons with implanted electrodes. Bulletin of the Psychonomic Society. $1974,4,141-143$.

Harsh, J., \& Badia, P. A concurrent assessment of the positive and negative properties of a signaled shock schedule. Animal Learning \& Behavior, 1974, 2, 168-172.

Miller, R. R., Daniel, D., \& Berk, A. M. Successive reversals of a discriminated performance for signaled tailshock. Animal Learning \& Behavior, 1974, 2, 271-274.

Woodard, W. T., \& Bitterman, M. E. Classical conditioning of goldfish in the shuttlebox. Behavior Research Methods \& Instrumentation, 1971, 3, 193-194.

(Received for publication May 19, 1975.) 